\title{
Tres familias de la oligarquía de Puebla de los Ángeles de la Nueva España durante el siglo XVII
}

Three families of the oligarchy of Puebla de los Ángeles de la Nueva España in the 17 th century

Agustín GRAJALES PORRAS

Benemérita Universidad Autónoma de Puebla, México agusgrajalesp@hotmail.com

Lilián ILLADES AGUIAR

Benemérita Universidad Autónoma de Puebla, México

lilianillades@gmail.com

\section{Resumen}

Las redes de poder que se entretejieron en la ciudad de Puebla desde fines del siglo XVI y durante el siglo XVII se asentaron sobre la base de relaciones políticas, económicas y de parentesco por sangre, afinidad y espiritual. Esta estrategia multifacética rindió sus frutos dando continuidad al poder transmitido a través de las generaciones. Tres son los troncos familiares que se siguen por cerca de un siglo en su participación en el Ayuntamiento de la ciudad, en sus actividades económicas, en la vinculación de bienes y en sus alianzas matrimoniales por atestiguamiento y compadrazgo.

Palabras clave: Red de poder; cabildo; familias; Puebla de los Ángeles; siglo XVII.

\begin{abstract}
The power networks in Puebla from the late sixteenth century to the end of the seventeenth century were based on political, economic and kinship relationships, whether based on blood, affinity, and spiritual ties. This versatile strategy allowed the continuity of power through generations. Three families are analyzed over a century, focusing on their participation in the city council, their economic activities, their entailed heritage and their marital alliances by witnessing and goodfatherhood.
\end{abstract}

Keywords: Power networks; city council; families; Puebla de los Ángeles; 17th century. 


\section{La ciudad y su cabildo}

En respuesta a las políticas colonizadoras de la Corona, Puebla se fundó en 1531 como una república para españoles no encomenderos que labraran la tierra, desempeñaran oficios y formaran familias cristianas. A partir de la treintena de fundadores, la ciudad vio crecer su población de manera notable en razón del asentamiento de nuevos pobladores atraídos por las concesiones y prebendas reales, la ubicación geográfica estratégica, la abundante mano de obra indígena circundante, la fertilidad de los campos, el clima y el sistema de ventas y mesones establecidos entre la costa atlántica y el altiplano mexicano. Al concluir la centuria el número de habitantes alcanzó la cifra aproximada de 9,000; tres décadas después rondaban 20,000 almas y en los años 1660 la ciudad contaba con alrededor de 35,000 (Grajales, 2007).

En el siglo XVII, Puebla se consolidó como un notable centro agrícola, comercial y manufacturero que contribuyó al desarrollo de la economía novohispana y concurrió en el comercio interocéanico mediante el consumo y redistribución de mercancías europeas y asiáticas. De manera importante intervino en el abasto de las flotas mercantes que anclaban en los puertos de Veracruz y Acapulco, así como de la Real Armada de Barlovento y del presidio de San Agustín en la Florida.

La ciudad y los valles adyacentes destacaron en la producción de granos, harinas, panes y bizcochos. Otros productos que circulaban en el mercado interno fueron los jamones, tocinos, manteca, jabones, vidrio, loza, sombreros, pieles curtidas, objetos de hierro forjado, instrumentos de labranza, paños y mantas, fabricados en los obrajes desde 1548 (Fernández de Echeverría, 1962: 299-300). Adicionalmente, Puebla descolló en el comercio de la grana proveniente de Antequera.

En el contexto virreinal, la ciudad se distinguió por el volumen de su población, su economía y como centro cultural y religioso, sólo rebasada por la capital del virreinato. La distinción oficial como la segunda ciudad novohispana más importante fue solicitada por el cabildo a los pocos años de su fundación. Los regidores también solicitaron a la Corona que de febrero a septiembre de cada año la Real Audiencia residiera en la Ciudad de México y el resto de los meses en Puebla (Fernández de Echeverría, 1962: 140). Al mismo tiempo, la primigenia silla episcopal del continente, asentada en Tlaxcala, fue trasladada a Puebla en 1543. En el transcurso del siglo XVII, la administración eclesiástica de la ciudad estaba sustentada en las parroquias y doctrinas de El Sagrario de la Catedral, San José, San Sebastián, Santo Ángel Custodio y la Santa Cruz. Bajo el impulso del clero regular y del secular proliferaron iglesias, conventos, monasterios, capillas, colegios, casas de recogimiento, asilos, orfanatos y hospitales. La clerecía asistió a una población en 
ascenso, congregada en la traza urbana española y en barrios, molinos, ranchos, haciendas y pueblos de indios.

A finales del siglo coexistían los grandes grupos socioétnicos: españoles, indios, mestizos, negros y mulatos. El 38\% del total eran españoles y siete de cada diez de ellos residían en la jurisdicción central de El Sagrario. Los indios representaban el 32\%, cuya mitad habitaba en la traza española (Grajales, 2007: 257; López de Villaseñor, 2001: 430)1․ El resto de los habitantes lo componían los mestizos y las castas, quienes se asentaron en el centro urbano en la misma proporción que los españoles. A la inicial población mestiza se le impidió instalarse en los espacios destinados a los indios, por lo cual convivió con los vecinos blancos. La prohibición se extendió a mulatos y negros; estos últimos habían llegado como esclavos desde el siglo XVI. Para 1692 se contaban alrededor de 84,000 habitantes (Grajales, 2007: 243).

La importancia que cobró la ciudad obedeció a su organización económica, política, administrativa, eclesiástica y cultural, al número de sus moradores, a su diversificación social, a la traza urbana y su riqueza arquitectónica, al tamaño de su término jurisdiccional y a las villas, pueblos y explotaciones agrícolas que dependieron del concejo asentado en la cabecera municipal.

El cabildo fue la institución política representativa de las ciudades, encargado de su administración y virtualmente del buen gobierno. El cuerpo colegiado vertebraba la vida de las poblaciones porque tenía injerencia directa en la impartición y aplicación de la justicia, en la seguridad y salud públicas, en el ordenamiento urbano y las obras; administraba las propiedades de la ciudad, expedía títulos de vecindad, repartía solares urbanos, tierras, aguas y pastos. El ayuntamiento controlaba la economía a través de la regulación del comercio, tránsito de personas y mercancías, abasto de granos, carnes, establecimiento de los precios de numerosos productos, supervisión de los pósitos, alhóndiga, rastro, Real Almoneda y la organización gremial y profesional del trabajo².

Era cometido del cabildo civil, tanto como del eclesiástico, la celebración de festividades y ceremonias públicas. Con ostentación y parafernalia se vivían las juras y exequias reales, el paso de virreyes y obispos, las conmemoraciones religiosas y fiestas patronales. El despliegue dramático de tales actos buscaba ganar fama y enaltecer el honor de la ciudad a fin de posicionarla en el concierto de ciudades del imperio español para la obtención de privilegios.

\footnotetext{
1 Desde mediados del siglo XVI se había legalizado el asiento de los naturales mediante la formación de repúblicas que contaban con su propio gobierno y, en 1560, se regularizó su vivienda en el casco español al repartírseles un cuarto de solar a muchos de ellos.

${ }_{2}$ Consejo de Indias, España (1841): Recopilación de leyes de los Reinos de Indias, Madrid, Boix editor, tomo II, libro IV, título XII, ley II.
} 
Bajo Felipe II inició la venta de cargos en las Indias con el fin de obtener una fuente más de ingreso para las arcas; entre ellos, las regidurías, sin que esto se extendiera a los alcaldes ordinarios, cuya elección era anual. Con Felipe III, los cargos se llevaron a pública almoneda para rematarse en su justo valor ante oficiales de la Real Hacienda. En la disposición estaba previsto que el remate del cargo vacante debía favorecer a individuos capaces, con lustre y que preferentemente fueran conquistadores, colonos o sus descendientes ${ }^{3}$.

Por la falta de rectitud y limpieza con la que procedieron los cabildantes en el ejercicio de sus funciones, les estaba vedado bajo pena de privación del oficio hacer tratos y contratos en granjerías de labranza, crianza de ganado, bastimentos de pan, carne, fruta y otros productos destinados al abasto común. No debían poseer tiendas, tabernas ni obrajes, tampoco podían practicar la reventa de productos, ni usar oficios viles dentro de los términos de las ciudades, villas y pueblos 4 .

Con la aprobación real, los cargos municipales vendibles y renunciables se instituyeron en 1612 en los cabildos de las dos ciudades más importantes del virreinato: México y Puebla (Fernández de Echeverría, 1962: 144). La Corona había concedido la perpetuidad en los cargos y con su venta condujo al surgimiento y fortalecimiento de importantes grupos de poder en las Indias. A lo largo del reinado de la Casa de Austria la estructura y el funcionamiento de los cabildos novohispanos se fue modificando, de instituciones originariamente de perfil electivo se convirtieron en espacio e instrumento que facilitaron la cohesión y permanencia de gobiernos locales integrados por pocos individuos que cedían normalmente las regidurías a sus hijos. El dominio del cabildo fue esencial porque constituía el instrumento más poderoso de los grupos de poder locales. Desde finales del siglo XVI, el cabildo de Puebla desbordó la docena de ediles previstos en la legislación indiana. En 1597, al regidor Gaspar Gómez de Vasconcelos se le nombró representante de la ciudad para obtener la merced real que otorgaba el derecho de contar con catorce regidores5. El número se incrementó en las décadas centrales del siglo XVII, para culminar con veinte concejales en la última década.

Las diferentes posturas en relación con la composición del cabildo son evidentes desde inicios del siglo mencionado: el regidor Pedro de Uribe, mercader, contraviniendo la normativa por su actividad, consideraba el riesgo que representaba para los intereses de la ciudad los lazos de parentesco que unían a miembros del cabildo, ya que se elegían unos a otros para ocupar la alcaldía ordinaria o las regidurías. En contrapartida, el regidor Martín de Mafra Vargas, se escandalizaba de la prohibición para votar por hermanos, cuñados o cualquier otro

${ }_{3}$ Ibidem., tomo II, libro III, título II, ley XIV.

4 Ibidem., tomo II, libro V, título III, leyes XI-XI.

5 Acta de Cabildo, Puebla, 7 de noviembre de 1597, Archivo General Municipal de Puebla (AGMP), Libros de Actas de Cabildo, vol. 13, f. 18v. 
pariente, al considerar que esta medida iba en detrimento de la ciudad (Peña, 1983: 168).

Desde los albores del siglo XVII, el cabildo de Puebla estuvo controlado por propietarios de tierras, comerciantes y obrajeros que desplazaron paulatinamente a los descendientes de conquistadores y fundadores de la ciudad. Este grupo de regidores convirtió al ayuntamiento en uno de los más importantes núcleos de poder del virreinato.

Las familias que dominaron la escena política de la ciudad y su jurisdicción forjaron un poderoso patrimonio sustentado en haciendas de labor, estancias ganaderas, trapiches, obrajes, molinos, batanes, tratos comerciales, recuas, inmuebles urbanos, hipotecas y créditos, entre otros negocios (Peña, 1983: 171180). Otro ámbito no descuidado por las familias fue su vinculación con el brazo eclesiástico, incorporando a alguno de sus miembros en el clero regular masculino y femenino, así como en el secular. Fundaron capellanías, instituyeron obras pías, participaron en cofradías y patronazgos religiosos e incluso penetraron en el aparato inquisitorial, desempeñándose como familiares del Santo Oficio.

En la composición del cabildo hubo la constante presencia de miembros de familias acaudaladas a lo largo de varias generaciones: López Berrueco, Machorro, Pérez de Salazar, Anzures, Hidalgo, Guevara, Aguayo, Díaz de Herrera, Cerón Zapata y Narváez, entre otras. Un prototipo de las estirpes mencionadas son las Ramírez de Arellano, Carmona Tamariz y Gómez de Vasconcelos, cuyos integrantes conformaron en el transcurso del tiempo poco más de la quinta parte, en promedio, de los regidores.

\section{Familia Ramírez de Arellano}

Felipe Ramírez de Arellano y Navarra, fundador de la estirpe que instituyó un mayorazgo en Puebla arribó a la Nueva España a mediados del siglo XVI. En la ciudad de los Ángeles, desposó a Juana de Aguilar y Ceballos, hija de García de Aguilar6, uno de los fundadores de la Puebla, quien fue su alcalde ordinario en 1534, 1536, 1547 y 1555 (Fernández de Echeverría, 1962: 170-172). Los enlaces entre peninsulares y criollas adineradas, ambos pertenecientes al estamento social más alto, fueron una práctica secular en la formación de grupos familiares.

Juana fue dotada con propiedades urbanas y rústicas, cuyo valor ascendía a 13,000 pesos; parte de los bienes provenían de la encomienda que obtuvo su padre en la Mixteca Alta (Fernández de Echeverría, 1962: 170-172; Fernández del Campo, 1997: 80-81)7. Como la mujer con su dote, el marido contribuía al matrimonio con

${ }^{6}$ Acta de Cabildo, Puebla, 25 de agosto de 1533, AGMP, Libros de Actas de Cabildo, vol. 3, f. 14v.

7 Actas de Cabildo, Puebla, 25 de agosto de 1533 y 1 de junio y 16 de diciembre de 1554, AGMP, Libros de Actas de Cabildo, vol. 3, f. 14. y vol. 7, ff. 27 y 51-52. 
su propio capital; además, debía donar a su esposa, en calidad de arras, la décima parte de sus bienes. El hombre se encargaba de la administración de lo aportado por ambos, aunque cada uno mantenía la propiedad de sus caudales y sólo compartían los gananciales producidos. El vínculo matrimonial se convirtió en una táctica para preservar e incrementar la riqueza de las familias pudientes; además, otro elemento esencial para la concertación de matrimonios fue el tejido de relaciones sociales que aportaban los contrayentes (Artís Espriu, 1994: 67, 71, 73, 75 y 91).

El 1 de junio de 1554, Felipe recibió la merced de título de vecindad otorgada por el cabildo, mismo año en que ejerció como alcalde mayor. Pasados más de dos años, el 31 de julio de 1556, el cabildo le otorgó una suerte de tierra en el cercano y fértil valle de Atlixco9; la merced fue la semilla que fructificó en un mayorazgo. El 1 de enero de 1561, como solía suceder, el cabildo se reunió para elegir a los alcaldes ordinarios; en esa ocasión la votación favoreció a Felipe10. Con esta elección, la familia inició su participación en el gobierno local como alcaldes del ayuntamiento, de la Santa Hermandad y tenientes de alcalde mayor, con excepción de un nieto, quien fue el único que ocupó un asiento en el cabildo.

En octubre del mismo año los capitulares acordaron dirigirse a su alcalde ordinario pidiéndole que residiera en la ciudad para que se encargara de su oficina 11 . Con seguridad, el alcalde aprovechaba más su tiempo en el valle de Atlixco, donde tenía varias propiedades, y en respuesta argumentó que no podía continuar con el cargo, razón por la que fue sustituido12; no obstante, al año siguiente, fue elegido alcalde de la Santa Hermandad13. En 1566, Felipe conjuntó el cargo de la Santa Hermandad con el de alcalde ordinario y alcalde de la Mesta, oficios que le otorgaban poder, control y salvaguarda de los caminos y del tránsito de sus mercancías, al mismo tiempo que de los ganados y pastos. Este último cargo lo mantuvo por un bienio14. Aparentemente Felipe no tuvo ningún encargo en el gobierno local durante catorce años, pero en 1580 fue electo, por última vez, alcalde ordinario de primer voto y al mismo tiempo de la Santa Hermandad (Fernández de Echeverría, 1962: 174)15, un día después fue designado juez de bienes de difuntos ${ }^{16}$.

8 Acta de Cabildo, Puebla, 16 de diciembre de 1554, AGMP, Libros de Actas de Cabildo, vol. 7, ff. 5152.

9 Actas de Cabildo, Puebla, 1 de junio de 1554 y 31 de julio de 1556, AGMP, Libros de Actas de Cabildo, vol. 7, ff. 27 y 130.

10 Acta de Cabildo, Puebla, 1 de enero de 1561, AGMP, Libros de Actas de Cabildo, vol. 8, f. 119v.

11 Acta de Cabildo, Puebla, 17 de octubre de 1561, AGMP, Libros de Actas de Cabildo, vol. 8, f. 142.

12 Acta de Cabildo, Puebla, 24 de octubre de 1561, AGMP, Libros de Actas de Cabildo, vol. 8, f. 142v.

13 Acta de Cabildo, Puebla, 1 de enero de 1562, AGMP, Libros de Actas de Cabildo, vol. 8, f. 146v.

14 Acta de Cabildo, Puebla, 1 de enero de 1566 y 1 de enero de 1567, AGMP, Libros de Actas de Cabildo, vol. 10, ff. 4v y 25.

15 Acta de Cabildo, Puebla, 1 de enero de 1580, AGMP, Libros de Actas de Cabildo, vol. 11, f. 41.

16 Acta de Cabildo, Puebla, 2 de enero de 1580, AGMP, Libros de Actas de Cabildo, vol. 11, f. 44. 
Estando en funciones, en el mes de agosto, le sobrevino la muerte (Fernández de Echeverría, 1962: 174)17.

El matrimonio formado por Felipe Ramírez de Arellano y Juana de Aguilar instituyó un mayorazgo en 1575. La escritura de fundación contiene llamamientos y sucesiones con respecto a su transmisión; en algunos puntos del clausulado se establece que en caso de no existir prole legítima, se haría entrega de los bienes vinculados al siguiente hermano en orden de edad, y también se estipulaba que los albaceas testamentarios se beneficiarían de todas las rentas y productos de las fincas rústicas y urbanas durante el primer año transcurrido desde el deceso del otrora poseedor. En la escritura, también se especificaba la obligación del poseedor de restituir y reparar los bienes vinculados para que sin menoscabo alguno fueran recibidos por el sucesor 18 .

Los mayorazgos no prescribían y aseguraban la preservación de la riqueza en la que se sustentaba el esplendor de un apellido, los bienes que lo integraban eran indivisibles, no podían enajenarse, tampoco hipotecarse, ni arrendarse por un periodo mayor a una década, ni cederlos a perpetuidad. Esta institución establecía el monto y orden en que se transmitirían los bienes a manos del usufructuario del vínculo. Entre el resto de los hijos se dividía la parte de la riqueza que no había sido incluida en el mayorazgo. Esta fórmula se repetía en cada generación colocando a los descendientes menores en desventaja con relación al mayor.

Ramírez de Arellano y Juana de Aguilar procrearon al menos dos hijos: María y Juan. Ambos fueron bautizados en El Sagrario, ella, el 21 de enero de 1554, y él, el 14 de julio de 156119. Los hermanos fueron bautizados por el arcediano de la catedral, Francisco de León con licencia del cura del Sagrario, lo que muestra la estrecha relación de la jerarquía eclesiástica con las familias notables.

\footnotetext{
17 Actas de Cabildo, Puebla, 1 y 2 de enero de 1580 y 17 de agosto de 1580, AGMP, Libros de Actas de Cabildo, vol. 11, ff. 41, 44 y 63. Cuando don Felipe fungía como alcalde en 1566, Alonso de Arellano, presumiblemente su hermano, recibió la merced de un solar, y en 1582 consiguió otra de un medio solar. Alonso había sido designado teniente del alcalde mayor de la ciudad en 1578. El caudal que poseía le permitió ser el fiador de Carlos de Luna y Arellano cuando éste llegó a ocupar el cargo de alcalde mayor de la ciudad. Entre otros bienes, Alonso poseía dentro de la jurisdicción de Puebla una pedrera en el cerro de San Francisco y tierras en Amalucan, distante poco más de 8 kilómetros de la ciudad. En 1599, Alonso fue electo alcalde ordinario de primer voto y de la Santa Hermandad. Al año siguiente, se desempeñó como alcalde de la Mesta, y fue entonces cuando Alonso concluyó su participación en el gobierno de la ciudad. Actas de Cabildo, Puebla, 11 de marzo de 1566 y 25 de septiembre de 1582, 13 de octubre de 1578 y 27 de marzo de 1589, 1 de enero y 13 de abril de 1599 y 1 de enero y 9 de septiembre de 1600, AGMP, Libros de Actas de Cabildo, vol. 10, ff. 8v-9, vol. 11, ff. 8 y 125, vol. 12, ff. 131-132 y vol. 13, ff. 55 y 69, 94v y 120.

18 Testamentaría del capitán Felipe Ramírez de Arellano, Archivo General de la Nación, México, (AGNM), Instituciones coloniales, Real Audiencia, Tierras, contenedor 0773, volumen 1771 у 1772, expediente 1, años 1705-1732, ff. 1-16.

19 Bautismos de María y Juan Ramírez de Arellano Aguilar, Puebla, 21 de enero de 1554 y 14 de julio de 1561, APSCP, Libro de bautismos, ff. 16v y f. 34.
} 
A la muerte de don Felipe, la posesión del mayorazgo recayó en su hijo Juan Ramírez de Arellano y Cevallos, quien rondaba los 20 años. Éste desposó a Ana de Mercado, hija del regidor Alonso de Soria y de Elvira de León, yerno a su vez de Gonzalo Rodríguez de la Magdalena, conquistador y uno de los fundadores de la ciudad, regidor y alcalde ordinario en tres ocasiones (Peña, 1983: 170). Juan y Ana procrearon a Felipe y Alonso, sin que se sepa aún de mayor prole.

En 1612, Juan fue electo alcalde ordinario, así como de la Santa Hermandad. En ese año, su hijo Felipe Ramírez de Arellano -bautizado como el abuelo- junto con su tío político Gaspar Gómez de Vasconcelos, eran regidores del cabildo2 ${ }^{0}$. En 1615 y 1616, Juan fue nombrado teniente de alcalde mayor 21.

Felipe desposó a Inés Tamariz de Carmona el 25 de julio de 1607; en el enlace actuaron como testigos Diego de Mendoza, alcalde mayor, y Pedro de Anzures, alcalde ordinario. La consorte era hija del regidor Diego de Carmona Tamariz y de María Gómez de Vasconcelos22. La dote aportada por Diego para su hija ascendió a 40,000 pesos, 21,000 en moneda (Peña, 1983: 171). El monto dotado se fijaba en relación con las rentas anuales que obtenía de sus bienes el progenitor (Artís Espriu, 1994: 94). Inés había sido bautizada el 27 de enero de 1585 y apadrinada por el deán de la catedral, Thomás de la Plaza, y Ana Gómez, tía materna de la criatura, hija de Juan Gómez de Vasconcelos²3. La joven madrina se desposaría más tarde con el regidor Pedro Hernández Asperilla, quien recibió en 1598 el título de familiar del Santo Oficio del número uno de la ciudad de Puebla, en virtud de su fidelidad y la de su esposa 4 .

20 Acta de Cabildo, Puebla, 2 de enero de 1612 y 18 de marzo de 1612, AGMP, Libros de Actas de Cabildo, vol. 14, ff. 205v y 218.

${ }_{21}$ Actas de Cabildo, Puebla, 17 y 20 de noviembre de 1615 y 26 de agosto de 1616, AGMP, Libros de Actas de Cabildo, vol. 15, ff. 78-79v-80 y $118 \mathrm{v}$.

22 Matrimonio de Felipe Ramírez de Arellano y de Inés Tamariz de Carmona, Puebla, 25 de julio de 1607, APSCP, Libro de Matrimonios, f. 150.

${ }_{23}$ Bautismo de Inés de Carmona Gómez, Puebla, 27 de enero de 1585, APSCP, Libro de bautismos, f. 158.

${ }^{24}$ Acta de Cabildo, Puebla, 5 de mayo de 1588, AGMP, Libros de Actas de Cabildo, vol. 12, f. 112. Nombramiento del Santo Oficio de la Inquisición, Puebla, 16 de octubre de 1598, AGMP, Libros de Actas de Cabildo, vol. 13, f. 48. Alonso Ramírez de Arellano contrajo nupcias trece años después que su hermano Felipe; desposó a Catalina Zapata de Galbes, viuda de don Juan Cerón, siendo testigos de la boda el alcalde mayor, don Alonso Tello de Guzmán, los regidores Francisco Sánchez de Guevara y Juan de Narváez, así como el depositario general y regidor Juan de Carmona Tamariz, cuñado del hermano del contrayente. El matrimonio procreó a su primogénita Ana, apadrinada por el fiscal de la Audiencia de Manila, José de Zapata de Godínez, y a cinco varones: Felipe Antonio, Antonio, Alonso, Marcos y Juan, nacidos entre diciembre de 1621 y julio de 1631. Matrimonio de Alonso Ramírez de Arellano y de Catalina Zapata de Galbes, Puebla, 10 de enero de 1621, APSCP, Libro de Matrimonios, f. 74v. Bautismos de Ana y Felipe Antonio Ramírez de Arellano Zapata, Puebla, 6 de diciembre de 1621 y 15 de febrero de 1623, APSCP, Libro de bautismos, ff. 376 y 418. Bautismos de Antonio, Alonso, Marcos y Juan Ramírez de Arellano Zapata, Puebla, 20 de mayo de 1624, 29 de mayo de 1627, 25 de noviembre de 1628 y 4 de julio de 1631, APSCP, Libro de bautismos, ff. 13v, 130v, 196 y 323v. 
Felipe Ramírez de Arellano Mercado, sucesor del mayorazgo, fue el único regidor de la familia. El cargo costó 5,000 pesos de oro común, de los cuales, conforme a la legislación indiana, la tercera parte ingresó a las arcas de su majestad. Felipe tuvo acceso a la regiduría porque Diego Carmona Tamariz, su futuro suegro, renunció a su favor desde el 15 de mayo de 1594, no tomando Felipe posesión en el cabildo hasta el 19 de octubre de 160725, año de su boda, a los 21 años, contraviniendo la cláusula limitante de edad para un regidor (25)26. Desde la renuncia de Diego en la persona de Felipe transcurrieron trece años, por lo que el matrimonio con Inés había sido concertado cuando ambos contaban con nueve años de edad. Este matrimonio ejemplifica cómo podía acordarse, con años de antelación, la trabazón económica, social y política de las familias. El vínculo matrimonial no competía a la esfera privada de los contrayentes y podía incluso desbordar el ámbito familiar pues los arreglos tenían repercusiones en el grupo oligárquico (Artís Espriu, 1994: 71).

En 1608, el padre del novel regidor Felipe obtuvo licencia del cabildo para extraer piedra de ocho solares y construir un horno de cal; la vista de ojos para otorgar el permiso la realizó el vástago del solicitante junto con el alférez real. Durante 1610, Felipe fue nombrado obrero mayor de la ciudad27. Al año siguiente, se le designó para que junto con el contador Marcos Rodríguez Zapata, escribano mayor de cabildo, concertaran con el arzobispo de México y virrey de la Nueva España, fray García Guerra, y con la Real Hacienda, el nuevo asiento de alcabala28. El cabildo acordó que la ciudad pagaría una renta de 24,000 pesos anuales durante un periodo de quince años ${ }^{2}$. Al despuntar el año siguiente, el cabildo, insatisfecho con las condiciones pactadas en México, comisionó de inmediato a Diego Carmona Tamariz, suegro de Felipe, para renegociar los términos del asientoз 0.

Felipe Ramírez fue encomendero de la mitad de los pueblos de Ihualtepec y Sochiquilazala, en la Mixteca oaxaqueña; juez cobrador de tributos y alcabalas de Tehuacán y alcalde mayor de la provincia de Tepeaca; asimismo capitán del

\footnotetext{
25 Inventario de bienes, Puebla de los Ángeles, 28 de julio de 1622, Archivo General de Indias (AGI), Consejo de Indias, Inventario de bienes: Ramírez de Arellano, Felipe, ES.41091.AGI/23.10.263//MÉXICO, 262, N. 211. Los autos del inventario fueron presentados por Alonso Ramírez de Arellano, hermano y apoderado de Felipe, ante Juan de Cervantes Carvajal, alcalde mayor y teniente de capitán general de la ciudad de Puebla de los Ángeles.

26 Bautismo de Felipe Ramírez de Arellano Mercado, Puebla, 10 de noviembre de 1585, APSCP, Libro de bautismos, f. 162.

27 Actas de Cabildo, Puebla, 23 de febrero de 1608 y 2 de enero de 1610, AGMP, Libros de Actas de Cabildo, vol. 14, ff. 68 y f. 129.

28 Actas de Cabildo, Puebla, 18 de noviembre de 1611 y 26 de noviembre de 1611, AGMP, Libros de Actas de Cabildo, vol. 14, ff. 197-198.

29 Acta de Cabildo, Puebla, 7 de diciembre de 1611, AGMP, Libros de Actas de Cabildo, vol. 14, f. 202.

30 Acta de Cabildo, Puebla, 22 de febrero de 1612, AGMP, Libros de Actas de Cabildo, vol. 14, ff. 211v212.
} 
regimiento reclutado en 161731. En 1619 y 1620, el capitán fue nombrado teniente de alcalde mayor de Puebla y tuvo como fiador a su cuñado, el cabildante Juan de Carmona Tamariz ${ }^{2}$. Otra faceta de los negocios de Felipe fue la diversión del vecindario, a él se debió la construcción de una casa y teatro de comedias en la cuadra inmediata a la plaza pública, ya que el cabildo le otorgó una licencia con exclusividad por veinte años, sin que nadie pudiera tener corral en ningún otro sitio. Tal era la importancia de este tipo de negocios que la concesión fue confirmada por el virrey Diego Fernández de Córdoba, marqués de Guadalcázar33. El deceso del regidor ocurrió cuando tenía 37 años de edad, en los inicios de $1623^{34}$, por lo que su carrera edilicia sólo perduró tres lustros.

El matrimonio de Felipe Ramírez e Inés Carmona Tamariz dio a luz a Ana, nacida en 161035; a los 17 años deposó al alférez Cristóbal López Berrueco Meléndez de San Julián, hijo del regidor Alonso López Berrueco y de Ana Meléndez de San Julián; la bendición nupcial la impartió el doctor Juan Godínez Maldonado, tesorero de la catedral, y fueron testigos el canónigo doctor Luis Monsón y los regidores Francisco Méndez Monte y Juan Gómez de Vasconcelos ${ }^{36}$, tío de la desposada.

Otros dos hijos de Felipe e Inés fueron Alonso y Carlos; se conoce de su existencia porque su padre renunció en ellos el oficio de regidor de Puebla, aunque el cargo fue rematado en la real almoneda de la ciudad de México, ya que sus hijos no aceptaron la renuncia que hizo en favor de ellos su padre. La viuda, como legítima administradora de sus hijos, acudió al virrey marqués de Cerralbo para que ordenara la venta del cargo. La denunciante hubo de presentar fe de vida, carta de dote y otros títulos. El virrey le dio curso a la solicitud y firmó el mandamiento en el que se ordenaba la venta de la regiduría el 27 de febrero de 1626. El alférez Francisco de Aguilar cubrió la fabulosa cantidad de 12,500 pesos por el cargo, a

31 Inventario de bienes, Puebla de los Ángeles, 28 de julio de 1622, AGI, Consejo de Indias, Inventario de bienes: Ramírez de Arellano, Felipe, ES.41091.AGI/23.10.263//MÉXICO, 262, N. 211.

32 Acta de Cabildo, Puebla, 2 de septiembre de 1619 y 23 de abril y 17 de octubre de 1620, AGMP, Libros de Actas de Cabildo, vol. 15, ff. 257 y 284v y vol. 16, f. 13.

33 Acta de Cabildo, Puebla, 1 de junio de 1618, AGMP, Libros de Actas de Cabildo, vol. 15, f. 118v.

34 Inventario de bienes de Felipe Ramírez de Arellano, Puebla, 28 de julio de 1622, AGI, Consejo de Indias, México, 262, N. 211. Acta, Puebla, 2 de septiembre de 1619, AGMP, Libros de Actas de Cabildo, vol. 15, f. 257. Fianzas, México, 1621, AGNM, Instituciones Coloniales, Real Hacienda, Archivo Histórico de Hacienda (008), vol. 1419, exp. 34, f. 11. Actas de Cabildo, Puebla, 1 de junio de 1618 y 2 de enero de 1618, 31 de marzo y 28 de abril de 1623, AGMP, Libros de Actas de Cabildo, vol. 15, f. $118 \mathrm{v}$ y vol. 16, ff. 133, 145v y 147.

35 Bautismo de Ana Ramírez de Arellano Carmona Tamariz, Puebla, 12 de noviembre de 1610, APSCP, Libro de bautismos, f. 37.

36 Matrimonio de Ana Ramírez de Arellano Carmona Tamariz y Cristóbal López Berrueco, Puebla, 2 de abril de 1628, APSCP, Libro de matrimonios, f. 159. 
pesar de la oposición que presentaron varios regidores, entre ellos, Juan de Carmona Tamariz y Juan Gómez de Vasconcelos 37 , cuñados del difunto.

El mayorazgo recayó en el primogénito de Felipe e Inés, de nombre Juan, nacido en 160838. El heredero se casó con Leonor de Toro Muñoz de Heredia, hija de Alonso de Toro; con ella engendró a Alonso, Felipe (1636), Isabel (1638), Joseph (1640) y Juan (1642)39. Fuera del matrimonio, Juan tuvo a un hijo natural de nombre Antonio4 0.

En 1639, Juan fue electo alcalde ordinario de segundo voto y de la Santa Hermandad para ese año. Pasados tres años se le nombró repartidor de la real alcabala ${ }^{4}$, debiendo distribuir junto con otros dos comisionados la cantidad de 53,300 pesos correspondientes al 6\% del impuesto que debía cobrarse a los comerciantes 42 ; la recaudación de la alcabala de repartimiento y de viento sobrepasó el compromiso ya que ascendió a 57,178 pesos.

En 1643, los primos hermanos Juan Ramírez de Arellano Carmona Tamariz y Juan de Carmona Tamariz Gómez de Vasconcelos fueron nombrados contadores de la real alcabala; al mismo tiempo, el primero se desempeñó como juez de reales novenos, pero en este año sobrevino su óbito43. En el siglo XVII, desde 1607 hasta 1665 figuraron en las actas del cabildo distintos miembros de la estirpe Ramírez de Arellano, de algunos de ellos aún no se ha podido establecer su filiación.

Tres hijos legítimos de Juan Ramírez de Arellano: Alonso, Felipe y Joseph, se sucedieron en la posesión del mayorazgo por muerte del antecesor. Probablemente, el primogénito no contrajo matrimonio y murió sin descendencia, por ello, el vínculo recayó en el segundo hermano, el capitán Felipe Ramírez de Arellano, vecino de la villa de Carrión en el valle de Atlixco y nacido en la ciudad de los Ángeles. Dicho Felipe se adjudicó además el apellido Navarra, ostentado por sus antepasados. El 2 de febrero de 1660 tomó en matrimonio a Josepha de Amézquita Larios Yañes; la pareja fue bendecida por el rector del Colegio Real de San Pedro y San Juan de la

37 Acta de Cabildo, Puebla, 6 de mayo de 1626, AGMP, Libros de Actas de Cabildo, vol. 16, ff. 319 y 332.

38 Bautismo de Juan Ramírez de Arellano Carmona Tamariz, Puebla, 28 de julio de 1608, APSCP, Libro de bautismos, ff. $282 \mathrm{v}-283$.

${ }^{39}$ Bautismos de Felipe, Isabel, Joshep y Juan Ramírez de Arellano Toro, Puebla, 18 de abril de 1636, 8 de mayo de 1638, 21 de marzo de 1640 y 2 de agosto de 1642, APSCP, Libro de bautismos, ff. 6, 91, $170 v$ y 273.

40 Información matrimonial de Juan José Ramírez de Arellano y de María Orozco, Atlixco, 28 de junio de 1673, Archivo de la parroquia de Santa María de la Natividad de Atlixco (APSMNA), Libro de informaciones matrimoniales, 4 f.s.n.

41 Actas de Cabildo, Puebla, 1 de enero de 1639 y 12 de abril de 1642, AGMP, Libros de Actas de Cabildo, vol. 19, ff. 22 y 303 vta.

42 Acta de Cabildo, Puebla, 12 de abril de 1642, AGMP, Libros de Actas de Cabildo, vol. 19, f. 303vt.

43 Actas de Cabildo, Puebla, 2 de enero de 1643, 2 de septiembre de 1644 y 3 de marzo de 1665, AGMP, Libros de Actas de Cabildo, vol. 20, ff. 34-35, vol. 21, ff. 31v-32 y vol. 26, ff. 121-122 v. 
ciudad de Puebla, Felipe de Zabalza Amézquita44, seguramente pariente de la contrayente. Muy temprano, Josepha dejó viudo al capitán, siendo sepultada en el convento de Santa Clara de la mencionada villa. Ambos tuvieron una sola hija, quien tomó el hábito en el mismo convento, como religiosa de velo y coro con el nombre de Leonor de San Antonio; ahí sería investida de mayordoma y contadora mayor.

La preservación del patrimonio a través del estado matrimonial, condujo a los grupos de poder a que miembros de sus familias tomaran el estado eclesiástico. La dote de una desposada sería superior a la de una religiosa, quien mediante el celibato aseguraba que no hubiera divisiones sucesivas de la herencia (Artís Espriu, 1994: 69).

Tiempo después, el capitán engendró a dos hijos fuera de matrimonio con Clara Paramas y Quintanilla: Francisco y Juan. A la muerte del capitán, su hermano Joseph lo sucedió en el vínculo familiar a partir del 8 de junio de 170145. Éste contrajo matrimonio con Juana de Úbeda y Fonseca ${ }^{46}$ y engendraron al menos dos hijos: Juan José (1688) y Felipe (1695)47.

La propiedad urbana del mayorazgo de los Ramírez de Arellano se componía de la casa principal y huerta en el Alto de San Francisco; cinco casas y tiendas en el Portal de las Flores frente a la plaza mayor, en donde los bisabuelos habían fincado el vínculo, además de numerosos solares. La propiedad rural estaba constituida por cerca de una decena de haciendas de labor con sus tierras, aguas y aperos, estancias de ganado mayor y menor; agostaderos, molino de pan moler, menaje de casa que incluía plata labrada, joyas y carruajes, sirvientes y esclavos48. Joseph fue el último poseedor del mayorazgo durante el reinado de los Habsburgo.

\section{Familia Carmona Tamariz}

El primer Carmona Tamariz del que se tiene noticia fue Diego, natural de Granada en la península ibérica, quien llegó a la Nueva España a fines de la década de los años 1560. En 1593, Diego inició los trámites para obtener el nombramiento de familiar del Tribunal del Santo Oficio de la Inquisición (Salazar Juárez, 2001: 6566). En su probanza de sangre quedó asentado que descendía de cristianos viejos de

\footnotetext{
44 Matrimonio de Felipe Ramírez de Arellano y Josepha de Amézquita, Atlixco, 2 de febrero de 1660, APSMNA, Libro de matrimonios, f. 6.

45 Testamentaría del capitán Felipe Ramírez de Arellano, AGNM, Instituciones coloniales, Real Audiencia, Tierras, contenedor 0773, volumen 1771 y 1772, expediente 1, años 1705-1732, s. n. f.

46 Matrimonio de Joseph Ramírez de Arellano y Juana de Úbeda y Fonseca, Atlixco, 24 de agosto de 1686, APSMNA, Libro de matrimonios, f. 112.

47 Bautismos de Juan José y Felipe Félix Ramírez de Arellano de Úbeda y Fonseca, Puebla, 16 de junio de 1688, APSCP, Libro de bautismos, f. 321 Atlixco, 23 de septiembre de 1695, APSMN, Libro de bautismos, f. 32 .

48 Testamentaría del capitán Felipe Ramírez de Arellano, AGNM, Instituciones coloniales, Real Audiencia, Tierras, contenedor 0773, volumen 1771 y 1772, expediente 1, años 1705-1732, s. n. f.
} 
origen aragonés. Al año siguiente obtuvo el cargo honorífico, cuando contaba con 45 años (Salazar, 2001: 65-66).

A principios de la centuria siguiente, hizo las gestiones necesarias para obtener licencia para vincular parte de sus bienes. De la información que la Real Audiencia de México envió a la Corona en 1607, vertida por vecinos que atestiguaron en su favor, entre los que se cuentan un exalcalde mayor de Puebla, un alcalde ordinario, un regidor, un familiar del Santo Oficio, dos compadres y otros, se le presenta como un hombre rico y honrado, facultado para fundar un mayorazgo por cincuenta mil pesos en cabeza de uno de sus hijos, sin menoscabo del sustento para su esposa y sus otros dos hijos.

Diego era hijo legítimo de Hernando de Carmona, natural de Sevilla, e Inés de Santa Ana, natural de Toledo. Se le conocía desde que vivía en Granada y Sevilla, ciudades en las que residió con su familia antes de pasar a América. Los padres eran tenidos por cristianos viejos, de limpia casta y generación, descendientes de hidalgos. Un tío materno fue caballero del hábito de Santiago y un primo hermano, Alonso de Carmona, era familiar del Santo Oficio en Guatemala. Uno de los hermanos de Diego se llamaba Tomé y el otro, de nombre Bartolomé, era familiar del Santo Oficio en Granada. Una hermana de Diego estaba casada con otro familiar de la Inquisición en Sevilla.

En Puebla, Diego de Carmona Tamariz desposó a María Gómez de Vasconcelos. Ella era hija del vinatero Juan Gómez de Vasconcelos y de Ana García. $\mathrm{Su}$ padre era un rico mercader cuya fortuna rebasaba los 280,000 pesos en reales, granas, mercaderías y distintas posesiones de casas. Juan dotó a su hija con 30,100 pesos de oro común (Fernández del Campo, 1997: 57)49. El matrimonio Carmona Tamariz-Gómez de Vasconcelos formó su familia con cinco hijos: Inés, Juan, Hernando, Bartolomé y María, entre 1585 y 1591.

Diego y su mujer eran estimados por la gente principal de Puebla y respetados por todos. La casa que habitaban era muy frecuentada, vivían con gran fausto, tenían coches y escuderos, caballos, el aderezo de la casa era muy costoso, contaban con vajillas de plata, joyas, preseas de valor, mucho dinero amonedado, numerosos esclavos y esclavas y personal de servicio. Además de su morada principal, Diego poseía otros dos pares de casas igualmente importantes, ubicadas en la calle del Hospital de San Pedro; también tenía otros inmuebles que arrendaba. El matrimonio era propietario de molinos de pan moler en el río Atoyac, dos batanes en la ribera del río de San Francisco y catorce y media caballerías de tierra, cercanas a los batanes, en las que se cultivaba trigo y maíz. Los molinos y batanes valían 50,000 pesos, mientras que el conjunto de sus propiedades alcanzaba la cifra de

49 Bautismo de Ana Gómez de Vasconcelos García, Puebla, 24 de septiembre de 1570, APSCP, Libro de bautismos de españoles y mestizos, años de 1545-1591, vol. 1, s.n.f. Informaciones: Diego de Carmona Tamariz, 1607, AGI, Audiencia de México, México, 227, N. 27. 
150,000 pesos. Diego no tenía deudas y muchas personas le debían elevadas cantidades de dinero. Sus bienes no estaban censados.

La riqueza que había acumulado provenía de los obrajes que poseía, el comercio de ganado y de esclavos, la venta de mercancías procedentes de España y tiendas expendedoras de jamones y tocino, un trapiche, dos docenas de animales que empleaba en el transporte de sus mercancías: añil, grana cochinilla, cacao, pipas de vino y los géneros que adquiría al arribo del galeón de Manila (Salazar, 2001: 65-66; Fernández del Campo, 1997: 64-66 y 71-78)50.

El padre de Diego era un hombre de más de 85 años, cuya hacienda rebasaba los 35,000 pesos en bienes muebles y raíces; por lo tanto, Diego heredaría más de 10,000 ducados de Castilla, ya que aún no se le había entregado el legado de su madre. Así, Diego recibiría la herencia que le correspondería por la legítima paterna y la legítima materna, es decir, la mínima parte del patrimonio a la que tendrían derecho los descendientes de cada uno de sus padres.

La esposa de Diego heredaría de su octogenario padre, una cantidad superior a los 20,000 pesos de oro común; su hacienda se estimaba en más de 280,000 pesos: era obrajero, casateniente, prestamista, mercader, y se dedicaba al trato de grana enviándola a Castilla.

El primogénito, Juan, quien sería la cabeza del mayorazgo solicitado, se había graduado de bachiller en la Facultad de Cánones de la Real Universidad de Salamanca y proseguía estudios de abogacía en Sevilla. El segundo hijo sobreviviente de Diego, Hernando, vivía en Puebla, al igual que su hermana Inés.

El parecer de la Real Audiencia fue el siguiente: el total de los bienes y hacienda del solicitante se estimó en más de 180,000 pesos. Las propiedades que se pretendía vincular rentaban anualmente más de 3,000 pesos, cantidad que iba en ascenso conforme transcurría el tiempo. Su mujer heredaría más de 50,000 pesos y él 10,000 ducados. El matrimonio era noble, hijosdalgo y limpio de todo; por lo tanto, concurrían en los esposos todas las calidades necesarias para fundar el mayorazgo, el cual quedó instituido en la ciudad de Puebla en 160751. Hacia 1622, en la Nueva España se habían instituido alrededor de 50 mayorazgos, duplicándose en el transcurso del periodo virreinal (Peña, 1983: 220; Ladd, 1984: 103; Artís Espriu, 1994: 109).

La carrera política de los Carmona inició en febrero de 1585, cuando Diego se incorporó al cabildo de la ciudad con la compra que hizo por remate de la regiduría valuada en 4,550 pesos que quedó vacante tras la muerte del regidor Antón Hidalgo. $\mathrm{Al}$ año siguiente, Carmona se desempeñó como procurador mayor de la ciudad52. En

50 Informaciones: Diego de Carmona Tamariz, 1607, AGI, Audiencia de México, México, 227, N. 27.

51 Informaciones: Diego de Carmona Tamariz, 1607, AGI, Audiencia de México, México, 227, N. 27.

52 Actas de Cabildo, Puebla, 4 de febrero de 1585 y 2 de enero de 1586, AGMP, Libros de Actas de Cabildo, vol. 12, ff. 6v-8v y 36v-37. 
numerosas ocasiones compartió la sala capitular con su cuñado Gaspar Gómez de Vasconcelos, así como con Pedro Hernández Asperilla, su concuño. En 1588, por ejemplo, Hernández Asperilla era el alcalde ordinario, mientras que Diego y Gaspar ejercían como regidores5 3.

A pesar de que Diego renunció a la regiduría en 1594, siguió participando en el gobierno local al ser designado alcalde ordinario y alcalde de la Santa Hermandad en 1613 y 1616 (Fernández de Echeverría, 1962: 177), asimismo se le nombró fiel ejecutor, mientras su hijo Juan fungía como depositario general y su yerno Felipe Ramírez de Arellano como regidor. Diego falleció en 1618, rayando 70 años (Fernández de Echeverría, 1962: 177; Fernández del Campo, 1997: 64)54.

Su hijo Juan Carmona Tamariz, el varón de mayor edad, fue bautizado el 28 de julio de 158655 , el mismo año del ascenso de su padre al ayuntamiento de la ciudad. Contrajo nupcias en 1610 con Agustina Gómez Pastrana, hija del difunto regidor y obrajero Alonso Gómez y de Catalina de Pastrana. Agustina era propietaria de las tierras que por donación le había otorgado su abuelo materno para edificar un horno de cal y una huerta. Ella aportó al matrimonio una dote de 32,000 pesos. A la muerte de Alonso, la herencia paterna ascendió a 20,855 pesos con 7 tomines; mientras que Juan recibió de su padre 27,500 pesos y contaba con 10,000 pesos más, producto de su actividad comercial con mercancías de la tierra y de Castilla (Fernández del Campo, 1997: 67-68)56. El matrimonio procreó a nueve varones y cinco mujeres entre 1611 y 1630.

Los padres de los desposados fueron obrajeros, coincidieron como cabildantes de 1592 a 1594, año en que Carmona renunció al cargo, probablemente para continuar al frente de la producción de sus obrajes, sin verse perturbado por la vigilancia desatada por las autoridades virreinales en cuanto a la incompatibilidad de administrar o ser propietario de manufacturas de paños al mismo tiempo que regidor.

Alonso Gómez se arraigó en Puebla en 1579, año en que se le otorgó el título de vecindad. En 1592 compró por remate el cargo de regidor al pagar 4,600 pesos; sin embargo, los cabildantes se negaron a aceptar su nombramiento argumentando que Gómez era obrajero. La intervención del virrey Luis de Velasco obligó al cabildo

${ }_{53}$ Acta de Cabildo, Puebla, 1 de enero de 1588, AGMP, Libros de Actas de Cabildo, vol. 12, f. 103v.

54 Actas de Cabildo, Puebla, 1 de enero de 1615 y 1 de enero de 1616, AGMP, Libros de Actas de Cabildo, vol. 15, ff. 2 y f. 86v.

55 Bautismo de Juan de Carmona Gómez, Puebla, 28 de julio de 1585, APSCP, Libro de bautismos, f. 166.

56 Informaciones: Diego de Carmona Tamariz, 1607, AGI, Audiencia de México, México, 227, N. 27. Acta de Cabildo, Puebla, 19 de noviembre de 1610, AGMP, Libros de Actas de Cabildo, vol. 14, ff. 15916. PEÑA, Oligarquía y propiedad..., pp. 169 y 171. 
a recibirlo como regidor al contar con el testimonio de que Alonso había vendido su negocio. Al año siguiente, Alonso fue designado procurador mayor de la ciudad57.

El caudal que legó Gómez a sus deudos rebasaba los 70,000 pesos, provenientes de inmuebles urbanos, esclavos, dos batanes y el mismo número de obrajes, siendo el poseedor del mayor obraje a principios del siglo XVII, ahí laboraban 250 indios, muchos de los cuales estaban enganchados con su patrón por deudas, pero por otro lado, también se ocupó de la salvación de su alma cuando fundó una capellanía (Fernández del Campo, 1997: 59-62 y 68).

A partir de 1610, luego de pagar la extraordinaria cantidad de 30,100 pesos de oro común, Juan de Carmona obtuvo los cargos de regidor y depositario general a los 24 años. El joven letrado fue la primera persona de la ciudad en desempeñar el último cargo mencionado en el cabildo, el cual contaba con la prerrogativa de obtener 2.5\% de los bienes en litigio que estuvieran bajo su custodia (Peña, 1983: 145; Fernández de Echeverría, 1962: 177)58 y ocupar un lugar de preeminencia junto con el alférez mayor en la sala de cabildos. El rango de los oficios situaba en la cúspide a los cargos ligados a la recaudación y custodia de caudales, seguidos de las regidurías.

Al integrarse al cabildo, Juan Carmona no abandonó la actividad mercantil, contraviniendo la legislación vigente; comerciaba añil, textiles, sombreros de lujo, azúcar y otro tipo de géneros. En sociedad con su padre poseía un trapiche y trataba con los paños de su cuñado Pedro Gómez (Fernández del Campo, 1997: 69 y 110112). Juan recibió un sinfín de comisiones: diputado de la carnicería, obrero mayor, fiel ejecutor y procurador mayor, entre otras, por cada una de ellas los regidores recibían un sueldo adicional. En varias ocasiones hijo y padre coincidieron en el cabildo, al fungir Diego como teniente de alcalde mayor por ausencia del titular59. Mientras Juan fue depositario general, su padre tuvo la encomienda de renegociar con el virrey y la Real Hacienda las condiciones para el asiento de la alcabala en 1612, el cual se firmó por 15 años, al mismo tiempo que recibió el nombramiento de repartidor de la renta6 0 , designación reservada a los comerciantes.

La alcabala era la renta ordinaria más significativa que producía la actividad comercial. El gravamen era un derecho real ejercido mediante el pago de un tanto por ciento de lo que se vendía y permutaba. Esta renta tenía un carácter universal, salvo en los casos exceptuados por la ley6 ${ }^{1}$. En la Nueva España, la Real Hacienda era la institución responsable de la recaudación, pero en ocasiones se asentó la cobranza

57 Actas de Cabildo, Puebla, 15 de septiembre de 1579, 18 de noviembre de 1592 y 2 de enero de 1593, AGMP, Libros de Actas de Cabildo, vol. 11, f. 38 y vol. 12, ff. 232v y 215v-216v.

58 Acuerdo de Cabildo. Puebla, 16 de julio de 1610, AGMP, Libros de Actas de Cabildo, vol. 14, f. 150v.

59 Acta de Cabildo, Puebla, 31 de julio de 1630, AGMP, Libros de Actas de Cabildo, vol. 17, f. 213.

60 Actas de Cabildo, Puebla, 22 de febrero y 9 de abril de 1612, 7 de noviembre de 1617 y 27 de febrero de 1627, vol. 14, ff. 211v-212 y 221v, vol. 15, f. 163 y vol. 17, ff. 43v-44.

61 Recopilación de leyes..., tomo III, libro VIII, título XIII, ley primera y II. 
en los cabildos62, convirtiéndolos en brazos fiscales de la monarquía. Durante la mayor parte del siglo XVII, el cabildo poblano gozó de esa prerrogativa. En 1617, Juan de Carmona fue designado contador de la real alcabala6 3 y una década después negoció en México las condiciones del contrato para el nuevo asiento64. En varias ocasiones fungió como teniente de alcalde mayor por ausencia del titular65.

La última participación de Juan en el cabildo fue en febrero de 163166, antes de zarpar a las Islas Filipinas al servicio de su Majestad. Estando en Manila acaeció su muerte el 28 de noviembre del mismo año a los 45 años. De manera precavida, antes de partir, el capitán dejó a su mujer, Agustina Gómez, un poder fechado el 29 de marzo de 1631 en el puerto de Acapulco, para que nombrara a la persona que lo sustituyera como regidor y depositario general 67 .

El alférez Hernando, segundo hijo varón de Diego Carmona Tamariz, desposó en 1629 a María de Pastrana, emparentándose así con la familia de su cuñada. Este matrimonio fue el segundo poseedor del mayorazgo. Hernando y María procrearon a seis varones y tres mujeres entre 1631 y 1646; el segundo de los varones, bautizado el 30 de junio de 1632, fue nombrado igual que su padre y recibió el vínculo familiar cuando éste falleció en 1678. Hernando desposó a Agustina Ximenes de Salas, ambos engendraron a Sebastián Carmona Tamariz, quien fue bautizado en 1685, y a un hijo póstumo nombrado como su padre y abuelo, bautizado el 26 de julio de 168968. El primogénito Carmona Tamariz Ximenes, cuarto titular del mayorazgo, contrajo matrimonio con Teresa Peregrina Gómez de la Parra en 1708 (Leicht, 1967: 253)6 9.

En 1627, Hernando de Carmona Gómez de Vasconcelos también intervino en el gobierno local al recibir el nombramiento de juez contador de la real alcabala y un par de años después fue designado veedor de mataderos de vaca y carnero. Para el año de 1643, fue alcalde ordinario y de la Santa Hermandad, y también se le nombró juez diputado y fiel ejecutor. Otros miembros de la familia que se beneficiaron fueron el presbítero Francisco de Carmona quien se desempeñó como capellán del cabildo 70 .

\footnotetext{
62 Ibidem., ley XLVI.

63 Acuerdo de Cabildo, Puebla, 7 de noviembre de 1617, AGMP, Libros de Actas de Cabildo, vol. 15, f. 163.

64 Acuerdo de Cabildo, Puebla, 27 de febrero de 1627, AGMP, Libros de Actas de Cabildo, vol. 17, f. $43 \mathrm{v}-44$.

65 Acuerdo de Cabildo, Puebla, 31 de julio de 1630, AGMP, Libros de Actas de Cabildo, vol. 17, f. 213.

66 Acta de Cabildo, Puebla, 21 de febrero de 1631, AGMP, Libros de Actas de Cabildo, vol. 17, f. 256.

67 Acta de Cabildo, Puebla, 13 de octubre de 1638, AGMP, Libros de Actas de Cabildo, vol. 19, f. 9.

68 Bautismo de Fernando Carmona Tamariz Ximenes, Puebla, 26 de julio de 1689, APSCP, Libro de bautismos, f. 51.

69 Matrimonio de Sebastián Carmona de Tamariz y Teresa Peregrina Gómez de la Parra, Puebla, 16 de septiembre de 1708, APSCP, Libro de matrimonios, f. 13 fte.

70 Acuerdos de Cabildo, Puebla, 3 de septiembre de 1627, 2 de enero de 1629 y 2 de enero de 1631, AGMP, Libros de Actas de Cabildo, vol. 17, , ff. 76, 140 y 241v.
} 
Los hermanos Juan y Hernando de Carmona Tamariz intervinieron en la formación de batallones con destino a las Islas Filipinas. Juan fue nombrado capitán, mientras que Hernando se convirtió en alférez ${ }^{11}$. La formación de batallones novohispanos y su sostenimiento, a costa de los ingresos de las ciudades, llevó a las autoridades locales a reclamar el derecho de nombrar a los capitanes de milicias; por ello, numerosos miembros de las familias del ayuntamiento obtuvieron el grado de capitán y en menor medida, de alférez.

La familia Carmona Tamariz intervino decididamente en el gobierno de la ciudad y también se favoreció durante su larga gestión. Por ejemplo, en 1612, el cabildo les mercedó a Juan y a su esposa, cuatro cuadras y el ojo de agua dulce del río Atoyac. A Diego se le mercedó un solar en el barrio de San Francisco en 1614. A Hernando, en 1626, se le mercedó una cuadra de tierra en el barrio de San Sebastián 72.

El tercer miembro de la familia que formó parte del cabildo de la ciudad fue otro Juan, hijo del primero del mismo nombre, nacido el 23 de diciembre de 1615. Fue capitán, regidor y el segundo depositario general del cabildo por 26 años, desde 1642 hasta 1668. Entre los dos Juanes, padre e hijo, controlaron ese cargo cerca de medio siglo.

Juan de Carmona Tamariz Gómez Pastrana no obtuvo el beneficio de la renuncia del padre porque contaba con 15 años y, además, a la viuda se le negó el derecho de designar al sucesor puesto que se argumentó que la noticia del deceso en las Filipinas llegó a destiempo conforme lo marcaba la legislación. Once años después los cargos fueron subastados y la única postura que se presentó fue la que hizo el hijo del finado, quien ofreció 4,000 pesos en 1642. Como el precio propuesto fue muy bajo, la oferta fue rechazada. Para resolver el asunto, se pidió el parecer del virrey Juan de Palafox y Mendoza, obispo de Puebla, quien aprobó el remate en favor de Juan73. Pasados tres meses, Juan fue nombrado contador de la alcabala, juez diputado y fiel ejecutor, al igual que lo habían sido su padre y su abuelo, también ejerció el cargo rotativo de provincial de la Santa Hermandad, oficio que fue mercedado al cabildo en 1644. Este año, Juan fue designado procurador mayor y receptor de la alcabala ${ }^{4}$; asimismo, se le comisionó para que tratara, en calidad de

\footnotetext{
71 Acta de Cabildo, Puebla, 14 de septiembre de 1629, AGMP, Libros de Actas de Cabildo, vol. 17, ff. 175-176.

72 Actas de Cabildo, Puebla, 3 de agosto de 1612, 18 de enero de 1614 y 7 de agosto de 1626, AGMP, Libros de Actas de Cabildo, vol. 14, f. 241, vol. 15, f. 34v y vol. 17, ff. 6v-7.

73 Actas de Cabildo, Puebla, 29 de julio de 1642, AGMP, Libros de Actas de Cabildo, vol. 19, ff. 325335.

74 Actas de Cabildo, Puebla, 12 de septiembre y 28 de noviembre de 1642, 30 de marzo de 1644, 12 de enero de 1646 y 6 de julio de 1646, AGMP, Libros de Actas de Cabildo, vol. 20, ff. 4v-6v, 24-25, $147-169 v$ y vol. 21 , ff. 151 y $194 \mathrm{v}-195$.
} 
comisario, el asiento del gravamen con el virrey conde de Salvatierra75, debiendo solicitar la disminución de la renta.

Al igual que su padre, en 1658, Juan de Carmona también fue designado sustituto del alcalde mayor, recibiendo los nombramientos de justicia mayor y teniente de capitán general76. En 1665, a través de una real provisión de Felipe IV, Juan recibió la denominación de capitán de guerra, título por el que no pagaría media anata, ya que había sido capitán de infantería de una compañía que se levantó en la ciudad para el socorro de las Filipinas en 1648. El 15 de mayo de 1665, el virrey Marqués de Mancera lo designó justicia mayor de la ciudad y su jurisdicción 7 .

El cabildo poblano, constituido por hacendados con intereses mercantiles y manufactureros mantenía fuertes lazos comerciales con Filipinas y Sevilla, destacando en este intercambio la familia Carmona Tamariz, abastecedora de bizcocho y otros géneros indispensables para las flotas y el comercio de ultramar. El Consejo de Indias aprobó la solicitud que el cabildo presentó en 1605 para que a su cargo quedase el abasto de las flotas y no en particulares, como había sucedido. El argumento de los regidores fue que el cuerpo capitular protegería el abasto de la ciudad y el de las flotas, encargándose de las compras el alcalde mayor (Celaya, 2010: 114). En 1662, Carmona Tamariz envió al puerto veracruzano de San Juan de Ulúa quintales de bizcocho, libras de tocino, fanegas de haba holandesa y arrobas de arroz y frijol. Además de despachar bastimentos a la Armada de Barlovento, Juan también se encargó de trasladarlos al puerto de Acapulco, de donde zarpaba la nao que hacía el viaje al Oriente. El depositario general fue responsable del envío de las compañías que marcharían para el socorro del archipiélago y de soldados para el refuerzo de la flota de San Juan de Ulúa78. Otra forma que aprovechó el capitán Carmona para incrementar su riqueza fue gracias al mandamiento virreinal por el que se le otorgó licencia para comprar trigo, producir harina en su molino y vender el producto en puertos y en la totalidad de los lugares de su gobernación 79 .

La Corona estableció un sistema de transferencia de recursos denominado situado, que consistía en cubrir en numerario o en especie los requerimientos de abastecimiento y gastos de defensa de El Caribe, el Golfo de México y las Filipinas. Los caudales debían provenir de las cajas reales o instancias recaudadoras. En

75 Acta de Cabildo, Puebla, 22 de septiembre de 1646, AGMP, Libros de Actas de Cabildo, vol. 21, f. $215 \mathrm{v}$.

76 Acta Cabildo, Puebla, 8 de agosto de 1858, AGMP, Libros de Actas de Cabildo, vol. 24, ff. 392v-393.

77 Acta de Cabildo, Puebla, 1 de julio de 1665, AGMP, Libros de Actas de Cabildo, vol. 26, ff. 167v$168 \mathrm{v}$ y 173.

78 Actas de Cabildo, Puebla, 18 de septiembre de 1662 y 19 de abril, 11 de mayo y 6 de diciembre de 1663, AGMP, Libros de Actas de Cabildo, vol. 25, ff. 362-363, 429, 433-435 y 500v-501v.

79 Acta de Cabildo, Puebla, 6 de diciembre de 1676, AGMP, Libros de Actas de Cabildo, vol. 28, ff. 528 y $531 \mathrm{v}$. 
Puebla, la recaudación de la alcabala formó parte de este sistema de transferencias fiscales de la Hacienda Real. El virrey ordenaba la compra, el cabildo efectuaba las operaciones mercantiles con los abastecedores de la ciudad y realizaba el pago con cargo a la alcabala. En consecuencia, la negociación de los ocho contratos que se hicieron en el siglo XVII para el asiento de la alcabala fue muy importante por los intereses económicos y políticos que manejaba el gobierno local. La transferencia de recursos no sólo era de orden fiscal sino que incluía la formación de batallones de milicias, el mantenimiento de una tropa regular en Filipinas desde 1609 y el envío de sus remplazos (Celaya, 2010: 111-113 y 115-116).

En 1667, Juan desposó a sus 51 años a Inés de Rivadeneyra y Castilla; sus testigos de boda fueron los capitanes, regidores y cuñados Juan Machorro y Diego Antonio Gómez de Vasconcelos ${ }^{8}$, primo segundo de Juan. Los tres compartían las sesiones de cabildo. Sin prole, el depositario general se presentó por última vez en el cabildo del 27 de enero de 16681. Con él concluyó la participación de esta familia en el gobierno de la ciudad durante 56 años: Diego de 1585 a 1594, Juan de 1610 a 1631, y su hijo Juan de 1642 a 1668.

\section{Familia Gómez de Vasconcelos}

Los antepasados de los Gómez de Vasconcelos eran de origen portugués. Juan Gómez, el suegro de Diego de Carmona, fue vecino de una pequeña población cercana a Oporto; se casó con Ana García, originaria de la provincia castellana de Valladolid. La pareja emigró con destino a la Nueva España y echó raíces en la Puebla de los Ángeles82. Allí nacieron sus hijos: Gaspar, bautizado el 18 de enero de 1566, María, el 11 de mayo de 1568, y Ana, el 24 de septiembre de 1570. Ana fue llevada a la pila bautismal, por uno de los fundadores de la ciudad, Martín de Mafra, y en su acta se asentó que su padre era vinatero83.

En 1596 la ciudad mercedó a Juan Gómez de Vasconcelos una caballería de tierra (52.79 ha.) cercana al monte del Pinar en el partido de Nopalucan, sobre el camino entre Puebla y Perote, que lindaba con tierras de su hijo Gaspars4. Este

\footnotetext{
80 Matrimonio de Juan Carmona Tamariz Gómez e Inés de Rivadeneira, Puebla, 11 de diciembre de 1667, APSCP, Libro de matrimonios, f. 171v.

81 Acta de Cabildo, Puebla, 1 de junio de 1665, AGMP, Libros de Actas de Cabildo, vol. 26, ff. 167v168v y 173. Matrimonio de Juan Carmona Tamariz Gómez e Inés de Rivadeneira, Puebla, 11 de diciembre de 1667, APSCP, Libro de matrimonios, f. 171v. Acta de Cabildo, Puebla, 27 de enero de 1668, AGMP, Libros de Actas de Cabildo, vol. 27, f. 140.

82 Informaciones de hidalguía y limpieza de sangre, Puebla, año de 1732, Archivo General de Notarías de Puebla (AGNP), Fondo Etapa Novohispana, Sección Escribanos, Notaría núm. 4, escribano Diego Antonio Bermúdez de Castro, caja 258, s.n.f.

83 Bautismo de Ana Gómez de Vasconcelos García, Puebla, 24 de septiembre de 1570, APSCP, Libro de bautismos de españoles y mestizos, años de 1545-1591, vol. 1, s.n.f.

${ }_{84}^{4}$ Acta de Cabildo, Puebla, 20 de diciembre de 1596, AGMP, Libros de Actas de Cabildo, vol. 12, f. 376.
} 
criollo poblano fue el fundador de la cepa de cabildantes del mismo apellido que mantuvieron la regiduría desde 1586 hasta 1669. Con sólo 20 años, Gaspar accedió al cabildo comprando la regiduría por la enorme cantidad de 5,700 pesos ${ }^{8}$.

El joven regidor contrajo nupcias con Magdalena Daza de Silva el 10 de septiembre de 1589. El canónigo Alonso Hernández de Santiago los desposó y la ceremonia fue atestiguada por su hermana María con su esposo Diego, así como por su otro cuñado, Pedro Hernández Asperilla y el cura Tomás Ruiz de Zúñigas86. La familia de la contrayente era probablemente del mismo origen lusitano.

Familiares de Gaspar se beneficiaron con dotaciones de agua y tierras mientras aquél era regidor. En alguna ocasión la "vista de ojos" del terreno requisito indispensable para la asignación de mercedes- que se le concedió a Juan Gómez de Vasconcelos Daza de Silva la realizó su tío por afinidad Diego de Carmona Tamariz. Éste, junto con su cuñado Gaspar participaron en la inspección para la entrega de cuatro caballerías de tierra a favor de Juan Daza de Silva Pizarro, cuñado de Gómez de Vasconcelos8 7.

A inicios de 1598, Gaspar fue nombrado procurador mayor y repitió en 1601; además de que en numerosas ocasiones fungió como diputado y fiel ejecutor88. Para 1615 era el regidor más antiguo del cabildo y el último cargo que desempeñó fue como alcalde ordinarios 9.

A través de sus hermanas María y Ana, Gaspar emparentó como se ha mencionado con Diego Carmona Tamariz y con Pedro Hernández Asperilla López. A los concuños, Carmona y Asperilla, los ligaba además el subrepticio ejercicio de familiares del Santo Oficio. Asperilla poseía caballerías de tierra que lindaban con propiedades de su cuñado Gaspar. Pedro fue en varias ocasiones alcalde ordinario de la ciudad y alcalde de la Santa Hermandad. Como gran propietario de ganado, el cabildo lo eligió alcalde de la Mesta en la jurisdicción del obispado durante el año de 1607. Gracias a su caudal, Asperilla fungió como fiador de distintos aspirantes a cargos públicos e incluso fue acreedor del cabildo cuando éste requería mercaderías de su tienda para las fiestas citadinas. En 1612, consiguió el abasto de carne de

85 Informaciones de hidalguía y limpieza de sangre, Puebla, año de 1732, AGNP, Fondo Etapa Novohispana, Sección Escribanos, Notaría núm. 4, escribano Diego Antonio Bermúdez de Castro, caja 258, s.n.f. Acta de Cabildo, Puebla, 24 de diciembre de 1586, AGMP, Libros de Actas de Cabildo, vol. 12, f. 83.

86 Matrimonio de Gaspar Gómez de Vasconcelos y Magdalena Daza de Silva Pizarro, Puebla, 10 de septiembre de 1589, APSCP, Libro de matrimonios de españoles y mestizos, años de 1585-1615, vol. 1, s.n.f.

87 Actas de Cabildo, Puebla, 29 de marzo de 1593, 20 de diciembre de 1596, 2 de abril y 12 de agosto de 1605, AGMP, Libros de Actas de Cabildo, vol. 12, ff. 244 y 376 y vol. 13, ff. 298v-299 y 309v-310.

88 Actas de Cabildo, Puebla, 2 de enero de 1598, 2 de enero de 1601, 3 de abril de 1601 y 2 de enero de 1604, AGMP, Libros de Actas de Cabildo, vol. 13, ff. 25, 145, 153v y f. 253.

89 Actas de Cabildo, Puebla, 10 de octubre de 1615, AGMP, Libros de Actas de Cabildo, vol. 15, ff. 7677. 
novillo durante cuatro años mediante remate por 4,200 pesos. Como obligado del suministro, el estanciero también debía de proveer los toros que se lidiarían en las fiestas. En una ocasión le solicitaron 50 toros para las corridas que se llevarían a cabo en dos plazas citadinas ${ }^{9}$.

El hijo de Pedro y Ana, homónimo de su padre, fue alcalde ordinario en 1640 y continuó con los negocios paternos. Pedro Hernández Asperilla Gómez de Vasconcelos y su primo hermano, Hernando Carmona Tamariz Gómez de Vasconcelos, desposaron a las hermanas Catalina y María Pastrana de Herrera91. En su gestión como alcalde, Pedro alternó con su primo hermano Juan Gómez de Vasconcelos Daza de Silva. La hermana de Pedro, María, desposó a Juan Velázquez de Avilés, quien tomó la vara de alcalde ordinario y alcalde de la Santa Hermandad en dos ocasiones ${ }^{2} 2$.

Gaspar Gómez de Vasconcelos y su esposa Magdalena fueron los primeros criollos poblanos en la genealogía de los marqueses de Monserrat. De este enlace nacieron varios hijos entre los años de 1591 y 1609: Juan, quien falleció siendo muy pequeño, un segundo Juan, Isabel, Magdalena, Gaspar, Juana, Cristóbal, Ana, Josefa y Antonia. Al igual que sus padres, los infantes fueron bautizados por prebendados de la catedral y apadrinados por la familia de Gaspar: padres y hermanas con sus respectivos esposos 93 .

El matrimonio Gómez Daza poseía distintas casas en la ciudad, una de ellas, cercana a la iglesia de la Compañía de Jesús, fue la casa solariega de los marqueses; además, una extensa hacienda de labor en Amalucan con veinte caballerías de tierra y catorce "piezas" de esclavos negros, negras e hijos, plata labrada, joyas de oro y menaje de casa9 ${ }^{4}$.

En febrero de 1620, después de 34 años, Gaspar renunció a la regiduría en favor de su hijo Juan Gómez de Vasconcelos Daza de Silva, quien se incorporó al

\footnotetext{
90 Actas de Cabildo, Puebla, 5 de mayo de 1588, 16 de octubre de 1598, 1 de agosto de 1603, 1 de enero de 1606, 6 de julio de 1607, 6 de marzo de 1610, 23 de julio de 1611, 30 de julio de 1612, 9 de agosto de 1613 y 15 de septiembre de 1616, AGMP, Libros de Actas de Cabildo, vol. 12, f. 112, vol. 13, ff. 48 y 232v, vol. 14, ff. 2, 29, 47v, 136, 185v-186, 240 fte. y vol. 15, ff. 119v-120.

91 Acta de Cabildo, Puebla, 1 de enero de 1640, AGMP, Libros de Actas de Cabildo, vol. 19, f. 101. Matrimonio de Hernando de Carmona Tamariz y María de Pastrana, 12 de agosto de 1629, ASCP, Libro de matrimonios, f. 180. Bautismo de Francisco Carmona Tamariz Pastrana Herrera, 18 de julio de 1633, ASCP, Libro de bautismos de españoles, f. 410.

92 Actas de Cabildo, Puebla, 1 de enero de 1614 y 1 de enero de 1622, AGMP, Libros de Actas de Cabildo, vol. 15, f. 30 y vol. 16, f. 184.

9з Bautismo de los hijos de Gaspar Gómez de Vasconcelos y Magdalena Daza de Silva, Puebla, años de 1592-1608 y 1609, APSCP, Libro de bautismos de españoles y mestizos, años de 1592-1608, vol. 2, s.n.f., y año de 1609, vol. 3, s.n.f. Testamento de Gaspar Gómez y Magdalena Daza, Puebla, año de 1618, AGNP, Fondo Etapa Novohispana, Sección Escribanos, Notaría núm. 4, escribano Alonso Corona, caja 92, legajo de enero a noviembre, f. 150v.

94 Testamento de Gaspar Gómez y Magdalena Daza, Puebla, año de 1618, AGNP, Fondo Etapa Novohispana, Sección Escribanos, Notaría núm. 4, escribano Alonso Corona, caja 92, legajo de enero a noviembre, ff. 151-152v.
} 
cabildo tres meses después. Juan pagó 3,000 pesos, equivalentes a la mitad del valor del oficio. La primera vez que los cargos concejiles se renunciaban, la mitad de su precio ingresaba a las cajas reales y en las subsiguientes renuncias se entregaría la tercera parte del costo. Los renunciantes debían permanecer vivos durante veinte días después de haber hecho la renuncia para que ésta fuera válida. Ya fuera el renunciante o quien se viera favorecido por la renuncia debía dar parte de ésta en un lapso que no rebasara los sesenta días, de lo contrario era improcedente (Gantes, 2000: 284)95. A partir de ese momento los primos hermanos Juan Gómez de Vasconcelos Daza de Silva y Juan de Carmona Tamariz Gómez de Vasconcelos compartirían la sala capitular durante once años.

Recién llegado al cabildo, Juan Gómez de Vasconcelos fue nombrado juez, diputado y fiel ejecutor de la ciudad. Después se le designó obrero mayor durante el año de 1622, nombramiento que obtuvo en varias ocasiones. También fue elegido capitán de una de las compañías que se formaron para servir a su majestad96. Juan fue designado patrón de fiestas en 1642 y al año siguiente, procurador mayor de la ciudad. Al poseer dicho nombramiento expuso ante las autoridades virreinales la postura del cabildo en el intrincado asunto de la composición de tierras y aguas de la ciudad con el rey. En septiembre de 1643, el capitán Juan Gómez realizó la escritura de composición de tierras y aguas de Puebla, y en 1651 fue asimismo regidor del pueblo de la Resurrección, próximo a sus heredades y a las de su primo Hernando de Carmona Tamariz, ubicadas en Amalucan 97.

En 1644 Gómez de Vasconcelos intervino en la obtención para el cabildo del título de provincial de la Santa Hermandad del obispado; con la prerrogativa de que sus capitulares ejercieran el oficio de manera alternada cada año. Muy fructífero debió ser el cargo puesto que los concejales pagaron de sus haciendas personales 20,000 pesos, además de 500 pesos por el derecho de la media anata9 8 .

La larga participación de Juan Gómez de Vasconcelos en el cabildo, le permitió empatar su desempeño con dos sobrinos: Juan Ramírez de Arellano Carmona Tamariz y Juan de Carmona Tamariz Gómez Pastrana, regidor y depositario general. En 1646, Juan Gómez y Juan Carmona fueron designados receptores de alcabala, pero además, los tocayos negociaron las condiciones del nuevo asiento del gravamen. En 1649, tío y sobrino, junto con el regidor Diego Machorro, consuegro de Gómez de Vasconcelos, fueron comisionados para visitar al obispo Juan de Palafox y

95 Acta de Cabildo, Puebla, 30 de mayo de 1620, AGMP, Libros de Actas de Cabildo, vol. 15, ff. 292293. Confirmación de oficio, 14 de diciembre 1620, AGI, Audiencia de México, 182, N. 26.

96 Actas de Cabildo, Puebla, 30 de octubre de 1620, 3 de enero de 1622 y 26 de septiembre de 1629, Libros de Actas de Cabildo, vol. 16, ff. 13v y 84v y vol. 17, f. 177.

97 Actas de Cabildo, Puebla, 17 de septiembre de 1604, AGMP, Libros de Actas de Cabildo, vol. 13, ff. $273 \mathrm{v}-274 \mathrm{fte}$.

98 Actas de Cabildo, Puebla, 9 de abril de 1642, 2 de enero de 1643 y 30 de marzo de 1644, AGMP, Libros de Actas de Cabildo, vol. 19, f. 300v y vol. 20, ff. 32v-33v y 147-169v. 
Mendoza para informarle de la disposición del cabildo para festejar la consagración de la catedral 9 .

Gómez de Vasconcelos se desempeñó como tesorero, cargo por el que percibió 400 pesos en 1652, también se le nombró comisario para tratar el próximo asiento de alcabala, conforme a las condiciones establecidas por su sobrino el depositario general, Juan de Carmona. Años más tarde Vasconcelos fue designado contador de la real alcabala con un salario de 400 pesos; sin embargo, tuvo que ser sustituido en su encargo por su consuegro Diego Machorro al sobrevenir su deceso100. La prolongada trayectoria edilicia de Juan se extendió por 38 años, poco menos de dos tercios de su vida.

En 1624 Juan Gómez de Vasconcelos se había unido a María López Berrueco Meléndez de San Julián, hija del edil sevillano Alonso López Berrueco y Ana Méndez de San Julián, originaria de la provincia de Badajoz101. Con este matrimonio, los Gómez de Vasconcelos se ligaron a otra familia poderosa, los López Berrueco. Alonso arribó a la Nueva España en 1594, fue propietario de una hacienda en Tepeaca y en 1618 compró el cargo de regidor por 5,000 pesos. Suegro y yerno compartieron la sala capitular por 32 años 102 .

En 1633, el capitán Juan Gómez de Vasconcelos fue designado contador interino de la real alcabala y a la vuelta de un par de años fue nombrado, junto con su suegro, juez contador administrador del impuesto103. La familia López Berrueco mantuvo la regiduría en línea directa por tres generaciones: Alonso padre de 1618 a 1652, Alonso hijo a partir de 1653 hasta 1679, y Bernabé desde 1679 a inicios de 1689104. Fue así como los López Berrueco preservaron la regiduría por 71 años.

99 Actas de Cabildo, Puebla, 6 de julio, 13 de octubre y 28 de noviembre de 1646, 16 de marzo de 1647, 6 y 9 de febrero de 1649, AGMP, Libros de Actas de Cabildo, vol. 21, ff. 194v-195, 229-230, 240$242 v$ y vol. 22, ff. 25 y $41 v$ y $254-256$.

100 Actas de Cabildo, Puebla, 21 de junio y 27 de agosto de 1652, 26 de abril y 21 de octubre de 1658, AGMP, Libros de Actas de Cabildo, vol. 23, ff. 211v y 219v-220 y vol. 24, ff. 247v y 406.

101 Informaciones de hidalguía y limpieza de sangre, Puebla, año de 1732, AGNP, Fondo Etapa Novohispana, Sección Escribanos, Notaría núm. 4, escribano Diego Antonio Bermúdez de Castro, caja 258, s.n.f.

102 Informaciones de hidalguía y limpieza de sangre, Puebla, año de 1732, AGNP, Fondo Etapa Novohispana, Sección Escribanos, Notaría núm. 4, escribano Diego Antonio Bermúdez de Castro, caja 258. Matrimonio de Juan Gómez de Vasconcelos Daza de Silva y María López Berrueco Meléndez de San Julián, Puebla, 14 de enero de 1624, APSCP, Libro dos de matrimonios de españoles, f. 103. Información y licencia de pasajero a Indias de Alonso López Berrueco, criado de Diego López, vecino de Guadalcanal, hijo de Pedro García y Ana López, a Nueva España, 15 de junio de 1594, AGI, Contratación, 5248, N. 2, R. 51. Actas de Cabildo, Puebla, 3 junio de 1637, 11 de abril de 1618 y 30 mayo de 1620, AGMP, Libros de Actas de Cabildo, vol. 15, ff. 186-187 y 292-293 y vol. 18, f 234.

103 Actas de Cabildo, Puebla, 26 de febrero de 1633 y 2 de enero de 1635, AGMP, Libros de Actas de Cabildo, vol. 17, f. 377 y vol. 18, f. 79.

104 Actas de Cabildo, Puebla, 3 de enero y 5 de noviembre de 1689, AGMP, Libros de Actas de Cabildo, vol. 32, ff. 120-121 fte. y 173-180. 
Juan Gómez de Vasconcelos y María López Berrueco tuvieron cinco descendientes: Magdalena, Ana, María, Diego Antonio y Juan. El primer varón nació en mayo de 1638 y a sus 20 años adquirió por un tercio de su valor la regiduría perpetua de la ciudad, en virtud de la renuncia que hizo su padre en su favor, tanto como de su cuñado Juan Francisco Machorro, casado con Magdalena, al oficio de regidor y provincial de la Santa Hermandad 105.

El nuevo regidor fue juez diputado y fiel ejecutor, juez contador y administrador de la alcabala. Diego Antonio, su cuñado Machorro y Francisco Pérez de Salazar fueron los comisionados para tratar las condiciones del asiento de la alcabala en 1667 y participó en la hechura de las instrucciones para el nuevo contrato que elaboraron el propio Pérez de Salazar y sus primos los regidores Juan de Carmona Tamariz y Alonso López Berrueco106.

Diego Antonio Gómez de Vasconcelos en razón de que su descendiente inmediato apenas alcanzaba dos años de edad, renunció en favor del capitán Francisco de Zuasnavar, esposo de su hermana Ana, quien entró en funciones en agosto de 1669107. Vasconcelos ocupó el cargo sólo por once años, corto periodo si se compara con los años de permanencia en el cabildo de su padre y abuelo. La familia Gómez de Vasconcelos conservó la regiduría durante 83 años continuos.

Los enlaces matrimoniales de tres de los hermanos Gómez de Vasconcelos López Berrueco, aunados a los parentescos previos, hicieron posible que los primos segundos Juan de Carmona Tamariz Gómez Pastrana y Diego Antonio Gómez de Vasconcelos fueran regidores simultáneamente, pero además, este último era primo hermano del regidor Alonso López Berrueco. El tejido se extendió cuando Diego Antonio y el suegro de su hermana Magdalena, Diego Machorro, compartieron la sala capitular.

En 1606, Domingo Machorro, abuelo de Juan Francisco, obtuvo el título de vecindad y al año siguiente se integró al cabildo como regidor; en ese año también fungían en el cabildo Gaspar Gómez de Vasconcelos, abuelo de Diego Antonio, y su sobrino por afinidad Felipe Ramírez de Arellano. Con el paso de las décadas, Domingo, propietario de tres haciendas, se convirtió en algún momento en el regidor más antiguo del cabildo. Machorro renunció en 1642 a favor de su hijo el alférez

\footnotetext{
105 Acta de Cabildo, Puebla, 10 de diciembre de 1658, AGMP, Libros de Actas de Cabildo, vol. 24, f. $12 \mathrm{v}-22$.

106 Actas de Cabildo, Puebla, 31 de enero de 1659, 27 de septiembre de 1661, 2 de enero de 1662 y 22 de marzo y 23 de abril de 1667, AGMP, Libros de Actas de Cabildo, vol. 24, ff. 12v y 434, vol. 25, ff. $255 v$ y $285-286 v$ y vol. 27 , ff. $36 v$ y $48-50$.

107 Actas de Cabildo, Puebla, 7 de mayo y 1 de agosto de 1669, AGMP, Libros de Actas de Cabildo, vol. 27 , ff. 259-260v y $295 \mathrm{v}-300 \mathrm{v}$.
} 
Diego, quien juró al cargo al año siguiente108. Para ese entonces, Domingo se había desempeñado como regidor durante 35 años.

El 1 de enero de 1660, Diego Machorro asistió al cabildo para la elección de su hijo Juan Francisco como alcalde ordinario. Con ausencias prolongadas y presencias eventuales, transcurrieron los últimos años de la regiduría de Diego, cuya carrera edilicia abarcó dos décadas; al final de su vida, en 1663, ejercía como contador de alcabalas junto con Diego Antonio Gómez de Vasconcelos, cuñado de su hijo Juan Francisco. Por renuncia de su padre, el tercer Machorro se estrenó como capitular en el gobierno de la ciudad 109.

Juan Francisco Machorro, además de haber sido alcalde ordinario en 1648 y 1660, fungió como procurador mayor de la ciudad. En agosto de 1669 se presentó por última vez a la sesión de cabildo; en esa ocasión juró como regidor Francisco Zuasnavar, concuño de Machorro. Este último fue regidor sólo seis años, un breve lapso comparado con los que se mantuvieron en el cabildo sus ascendientes 110 . Los Machorro ocuparon la regiduría por 61 años. Por su parte, el capitán Zuasnavar también mantuvo una breve regiduría por haber fallecido en $1675^{111}$.

Cuatro años antes de su deceso, en enero de 1665, el capitán Diego Antonio Gómez de Vasconcelos López Berrueco había desposado a María Bravo de Lagunas. Cuando contaba con 31 años, Diego Antonio testó y murió en el mes de junio de 1669. Dos años antes, en 1667, la pareja bautizó a Francisco Xavier Diego Carlos, a quien su padre designó heredero universal de sus bienes cuando éste no alcanzaba los dos años112. Sin llegar a la edad de 20 el joven heredero desposó a la neogallega Nicolasa Plácida Francisca de Luna Arias, el 6 de julio de 1687113.

\footnotetext{
${ }_{108}$ Actas de Cabildo, Puebla, 11 de febrero de 1606, AGMP, Libros de Actas de Cabildo, vol. 14, f. 7v. Confirmación de oficio de regidor, AGI, Audiencia de México, México, 177, N. 63. Pleito entre los conventos de la Concepción y Santa Clara en contra de los herederos Diego Fernández de León, Ángela Ruiz y demás herederos de Domingo Machorro 1693-1706, AGNM, Instituciones coloniales, Real Audiencia, Tierras (110), Contenedor 0106, vols. 196-199. Actas de Cabildo, Puebla, 19 de junio de 1635, 20 de junio de 1642 y 30 de julio de 1643, AGMP, Libros de Actas de Cabildo, vol. 18, ff. 104105 , vol. 19, f. 321 y vol. 20 , ff. $68-74$ v.

109 Actas de Cabildo, Puebla, 1 de enero de 1660, 1 de enero y 29 de marzo de 1661 y 27 de febrero, 30 de marzo y 7 de mayo de 1663, AGMP, Libros de Actas de Cabildo, vol. 25, ff. 1-2v, 179, 208, 410, 419 y $444 \mathrm{v}-446 \mathrm{v}$.

110 Actas de Cabildo, Puebla, AGMP, Libros de Actas de Cabildo, Puebla, 1 de enero de 1648, 1 de enero de 1660, 8 de agosto y 24 y 25 de septiembre de 1669, AGMP, Libros de Actas de Cabildo, vol. 22, ff. $130 v-131$ y vol. 25 , f. $1-2 v$ y vol. 27 , ff. $295 v-305$ v y 314-320.

111 Acta, Puebla, 1 de agosto de 1669 y 13 de marzo de 1675, AGMP, Libros de Actas de Cabildo, vol. 27, f. 295 vta.-300 vta. y vol. 28, f. 344 vta.

112 Matrimonio de Diego Antonio Gómez de Vasconcelos López Berrueco y María Bravo de Lagunas, 14 de enero de 1665, APSCP, Libro de matrimonios de españoles, f. 113. Informaciones de hidalguía y limpieza de sangre, AGNP, Fondo Etapa Novohispana, Sección Escribanos, Notaría núm. 4, escribano Diego Antonio Bermúdez de Castro, caja 258, año de 1732, s.n.f.

113 Informaciones de hidalguía y limpieza de sangre. AGNP, Fondo Etapa Novohispana, Sección Escribanos, Notaría núm. 4, escribano Diego Antonio Bermúdez de Castro, caja 258, año de 1732, s.n.f.
} 
Francisco Xavier Gómez de Vasconcelos y Bravo de Lagunas, tataranieto del fundador de la familia en Puebla, con apenas 23 años, fue el primer marqués de Monserrat, un título beneficiado de Castilla por el que desembolsó 24,200 ducados y 6,000 pesos 114 . Los herederos ostentaron el privilegio hasta 1826, año que el gobierno mexicano suprimió los títulos nobiliarios. La adquisición de un título ennoblecía a los descendientes del primer propietario, tanto como a sus ascendientes (Artís Espriu, 1994: 68-69). El marqués ocupó puestos locales siendo alcalde provisor de la Santa Hermandad en 1692 y alcalde ordinario (Leicht, 1967: 228-229)115; cuando enviudó pasó al estado eclesiástico alcanzando la dignidad de deán de la catedral.

\section{Conclusiones}

A través de las fuentes utilizadas se evidencian las relaciones que se establecieron entre los personajes observados durante su participación en el cabildo, sea como regidores o como alcaldes, los nexos políticos fueron precedidos en gran parte por los enlaces matrimoniales, que a su vez fueron antecedidos por las fortunas acumuladas y las formas en que éstas se heredaron. Los inmigrantes peninsulares fundadores de dos de las dinastías se unieron con criollas de familias adineradas. El entretejido de redes familiares desarrolladas a través de las generaciones revela la voluntad de los peninsulares y de los criollos por mantener la cohesión de los grupos de poder, estrechando no sólo los lazos entre iguales de cepa española, sino también los de carácter económico y político.

El emparentamiento espiritual mediante el bautizo, por un lado, y por otro, el atestiguamiento del casamiento fueron prácticas esenciales para reforzar los vínculos entre las familias y sus conexiones políticas y económicas ostentando su preeminencia frente a otros grupos sociales. Todos los bautismos que se observaron se impartieron en la pila principal de la ciudad. Considerando la masa de compadres y comadres, la elección de los padres se orientó a los parientes consanguíneos y por afinidad (61\%),116 y fuera de la familia, el compadrazgo se apuntaló al convidar a varones de alto rango y del clero secular.

Otro elemento de análisis para mayor comprensión de las formas en que los grupos sociales se cohesionaban y se perpetuaban, está estrechamente relacionado con quienes participaban como celebrantes del bautismo. Más de la mitad pertenecía

\footnotetext{
114 Informaciones de hidalguía y limpieza de sangre. AGNP, Fondo Etapa Novohispana, Sección Escribanos, Notaría núm. 4, escribano Diego Antonio Bermúdez de Castro, caja 258, año de 1732, s.n.f. 115 Actas de Cabildo, Puebla, 1 de enero de 1692, AGMP, Libros de Cabildo, vol. 33, ff. 2-3.

116 Se logró conformar un cuerpo de análisis de 87 bautismos de las tres familias troncales: 55 varones y 32 pequeñas, lo que arroja un índice de masculinidad muy elevado en razón de que en la investigación se siguió en gran medida la línea masculina de los descendientes con intención de seguir la transmisión de las curules, los mayorazgos y el título de nobleza.
} 
a las altas esferas eclesiásticas: dignidades del cabildo, canónigos, racioneros y curas prebendados; además, el grupo de poder contaba con un abanico más amplio de sacerdotes para bautizar a sus hijos, familiares y miembros de la jerarquía secular y regular, quienes contribuyeron a dar solidez a la oligarquía poblana.

Todos los individuos que presenciaron y atestiguaron los 19 enlaces que se pudieron observar, pertenecientes a las tres familias seleccionadas, ostentaban los rangos más altos de la jerarquía social, política y eclesiástica: alcaldes mayores, alcaldes ordinarios y regidores; seculares del alto clero e individuos de caudal y prestigio. Entre los últimos se hallan los tres títulos de nobleza residentes en la ciudad: conde de Castelo, marqués de Altamira y marqués de Montserrate. Estos son tres de los ochenta títulos de nobleza que se otorgaron en la Nueva España entre 1529 y 1821 (Ladd, 1984: 11).

De manera similar a lo que se ha develado para el bautismo en cuanto a la selección de los celebrantes y sus características se reprodujo en los matrimonios: destaca la presencia de un obispo, 12 dignidades o prebendados, el cura rector de El Sagrario, tres seculares y dos religiosos, de los cuales poco menos de un tercio estaba emparentado con alguno de los desposados. El matrimonio consanguíneo suele ser potestad de la élite, y aquí sólo uno fue registrado: el que administró el marqués de Montserrate a su nieto, sucesor inmediato al marquesado, quien desposó a su prima hermana; ambos eran solteros y fueron dispensados en las banas antes y después del matrimonio por el obispo Domingo Pantaleón Álvarez de Abreu117.

Es indiscutible que la permanencia de estas familias en el gobierno local obedeció al derecho de transmisión de las regidurías perpetuas por renuncia. Por otro lado, las relaciones de parentesco que estas familias establecieron con otros linajes, fuera consanguíneo, por afinidad o espiritual, así como las formas de herencia -transmisión de mayorazgos, títulos de nobleza, dotes y testamentos- les permitió crear una organización social que compartía intereses en el ejercicio del gobierno de la ciudad incidiendo en la distribución de tareas y beneficios como el reparto de mercedes, el establecimiento de precios de variadas mercadurías, el abasto, el pago de contribuciones, la confección de las ordenanzas que regulaban todos los ámbitos de la vida urbana y en asuntos tan sensibles como la participación en festividades y conmemoraciones en las que se ponía en juego el honor y prestigio de la ciudad y de las familias pertenecientes a la oligarquía.

El estudio presentado permite observar la evolución familiar a través de varias generaciones. La primera generación fue la de los fundadores de las dinastías. En la segunda se evidencia la riqueza y relaciones sociales y familiares que los afirmaron socialmente como familias poderosas, a esta generación correspondió la 
renovación en las regidurías del cabildo, así como la expansión de sus negocios particulares y su mayor presencia en la contratación del asiento de alcabala y en la vida política virreinal, así como su ingreso a las milicias; también son patentes los vínculos y lazos familiares que por vía del matrimonio establecieron estas familias entre sí en esta segunda generación. En la tercera generación se corrobora la manera en que las familias ligaron cada vez más sus negocios a la administración virreinal al participar en las negociaciones para renovar la contratación de la recaudación alcabalatoria. Numerosos integrantes de las estirpes observadas intervinieron en la administración de la alcabala durante 70 años; por consiguiente, fueron cómplices de componendas y evasión fiscal, defraudando a la Corona por ser la alcabala un derecho real118. Miembros de estas familias también participaron en el abastecimiento de armadas, flotas y tropas, gracias a que continuaban presentes en la vida política municipal beneficiándose de los cargos que ocupaban en el gobierno de la ciudad. Esta tercera generación continuó ciñendo los vínculos familiares y conformó una auténtica casta social que se movió como una red de poder e influencia al tomar parte en el control del cabildo, origen de su poder político, y los negocios que desde la administración local podían emprender, de los que se incrementaba su poder económico.

Resulta innegable que la injerencia de éstas y otras familias en la administración de la Puebla bajo el reinado de la rama española de los Habsburgo, les permitió acrecentar su poder y honra a lo largo de las décadas, tiempo en que la ciudad alcanzó su época de mayor esplendor y riqueza, hasta que fueron desplazadas por la modernidad que llegó aparejada con la sucesión de la casa real en España a comienzos del siglo XVIII. El microcosmos que se ha analizado en esta ciudad se vislumbra como un espejo de la vasta e intrincada sociedad colonial y de la metrópoli peninsular.

Como muestra de las cercanas y entreveradas relaciones que estas familias establecieron, cabría mencionar, sin que sea acertijo, aunque lo parezca, que en 1628 un miembro de la familia Gómez de Vasconcelos fue testigo de la boda de su sobrina consanguínea en segundo grado, al ser primo hermano de la madre de la contrayente. Ésta, a su vez, era cuñada de la esposa de su tío y su sobrina por afinidad en segundo grado. La desposada y su tío también eran concuños, ya que la esposa de él y el marido de ella eran hermanos. Por último, el tío consanguíneo de la recién casada, también era tío por afinidad de su cuñado119.

117 Matrimonio de Antonio Tomás Gómez de Vasconcelos con Juana Inés de Vallarta, 4 de febrero de 1748, APSCP, Libro de matrimonios de españoles, ff. 171v-172.

118 Acta de Cabildo, Puebla, 29 de agosto de 1637, AGMP, Libros de Actas de Cabildo, vol. 18, f. 257v.

119 Juan Gómez de Vasconcelos Daza de Silva fue testigo de la boda de su sobrina consanguínea en segundo grado Ana Ramírez de Arellano Carmona Tamariz, ya que la madre de ésta, Inés de Carmona Tamariz Gómez de Vasconcelos era prima hermana de Juan; al mismo tiempo, Ana era cuñada de la esposa de su tío, María López Berrueco, a la vez que su sobrina por afinidad en segundo grado. La 


\section{Bibliografía}

Artís Espriu, G. (1994): Familia, riqueza y poder. Un estudio genealógico de la oligarquía novohispana. México, CIESAS.

Celaya Nández, Y. (2010): Alcabalas y situados. Puebla en el sistema fiscal imperial 1638-1742. México, El Colegio de México.

Consejo de Indias, España (1841): Recopilación de leyes de los Reinos de Indias. Madrid, Boix editor.

Fernández de Echeverría y Veitia, M. (1962): Historia de la Fundación de la Ciudad de la Puebla de los Ángeles en la Nueva España, su Descripción y Presente Estado. Puebla, Ediciones Altiplano, vol. 1.

Fernández Del Campo Espinosa, J. (1997): La participación de la oligarquía poblana en la economía colonial. Las familias Pérez de Salazar, Carmona Tamariz, Gómez, y Ramírez de Arellano (1610-1625). Tesis de licenciatura, Fundación Universidad de las Américas Puebla, Puebla.

Gantes Tréllez, M. (2000): “Aspectos socio-económicos de Puebla de los Ángeles (1624-1650)”, en C. Contreras Cruz y M. Á. Cuenya, coords., Ángeles y Constructores.

Mitos y realidades en la historia colonial de Puebla (Siglos XVI-XVII). México, Benemérita Universidad Autónoma de Puebla, pp. 207-317.

Gonzalbo Aispuru, P. (2005): Familia y orden colonial. México, El Colegio de México.

Grajales Porras, A. (2007): Estudio sociodemográfico de la Puebla de los Ángeles a fines del siglo XVIII. Tesis doctoral, Universidad Nacional Autónoma de México, México.

Kicza, J. E. (1986): Empresarios coloniales. Familias y negocios en la ciudad de México durante los Borbones. México, Fondo de Cultura Económica.

Ladd, D. M. (1984): La nobleza mexicana en la época de la Independencia, 17801826. México, Fondo de Cultura Económica.

Leicht, H. (1967): Las calles de Puebla. México, Compañía Editorial Continental.

contrayente y su tío también eran concuños, porque María López Berrueco, esposa de Juan, era hermana de Cristóbal López Berrueco, marido de Ana. Por último, Juan era tío por afinidad en segundo grado de su cuñado, al haberse casado con su sobrina consanguínea. 
López De Villaseñor, P. (2001): Cartilla Vieja de la Nobilísima ciudad de Puebla. Deducida de los papeles auténticos y libros antiguos 1781. México, Secretaría de Cultural del Gobierno del Estado de Puebla.

Peña, J. F. de la (1983): Oligarquía y propiedad en Nueva España (1550-1624). México, Fondo de Cultura Económica.

Salazar Juárez, G. L. M. (2001): La Comisaría General del Tribunal del Santo Oficio de la Inquisición 1571-1610. Tesis de maestría, Universidad Nacional Autónoma de México, México.

Fecha de recepción: 15 de agosto de 2020

Fecha de aceptación: 28 de noviembre de 2020 